\title{
Energy dissipation in the regulators using straight wall baffles
}

\author{
Jamal S. Makki ${ }^{a}$, Mohammad H. AL-Umar ${ }^{\text {b }}$, and Basim M. Al-Zaidia,c \\ ${ }^{\text {a }}$ Civil Engineering, University of Thi-Qar, Nasiriyah, Iraq; jamal_sahib.2000@yahoo.com. \\ ${ }^{\mathrm{b}}$ Civil Engineering, University of Thi-Qar, Nasiriyah, Iraq; mohammadhydar.20@ yahoo.com. \\ ${ }^{\mathrm{c}}$ Civil and Environmental Engineering, University of South Carolina, Columbia, South Carolina, USA; basim.alzaidi.@gmail.com.
}

\begin{abstract}
Dissipating the high kinetic energy of an open channel flow under sluice gates can have a significant impact on eliminating scoring of the riverbed at the downstream. This paper discusses the outcome of an experimental study consisting of 28 runs, with the aim of achieving minimum hydrodynamic forces and maximum energy dissipation downstream of hydraulic structures through stilling basins with directional diverting blocks, DDBs and straight wall baffle, and SWB. Stilling basins with a distinct configuration were made for this purpose. The hydraulic parameters that were involved were evaluated and experimentally analyzed using a rectangular flume in the hydraulic laboratory of the University of Thi-Qar, Thi-Qar, Iraq. Two different kinds of DDB models were made of wood with a triangular form, and the striate line impact wall hadindistinct dimensions. The study showed that the configuration characterized by two rows of DDB with SWB between them is the most effective in dispersing energy. Out of all the suggested constructions, the DDB are more effective with two or more rows, rather than the SWB, but they are subjected to forces in the flow direction.
\end{abstract}

\author{
Keywords:

\section{Corresponding Author: Jamal S. Makki} \\ Departement, Civil Engineering, University of Thi-Qar, \\ University \#, University of Thi-Qar \\ Address. Nasiriyah, Iraq \\ E-mail: jamal_sahib.2000@yahoo.com
} Energy Dissipation ; Straight Wall ; Baffles

\section{Introduction}

Water flowing under the sluice gates with high kinetic energy can cause erosion at the end of the regu-lators and contribute to failure if proper precautions are not taken. For this purpose, energy dissipators are provided to dissipate a sufficient amount of energy before the water enters the downstream channel. Even though the hydraulic jump is typically used for energy dissipation in the stilling basins, there is a need for safe stilling basins providing energy dissipation independent of the combination of chute blocks, baffle blocks, and the end sills usually equip the designed basins. Thus, stilling basins of distinct models are used to dissipate the energy of the flowing water and to create safe flow conditions in order to prevent the down-stream end of regulators from severe erosion. This can be achieved by reducing the forces that result from the high kinetic energy of the blocks within the stilling basins [1-4] . In this study, our goal is to dissipate the high energy of the flowing water and then diminish the resulting forces by creating several configurations of straight wall baffle arrangements within the stilling basin, where the baffle blocks stabilize the jump and dissipate the energy due to the impact.

Extensive and thorough research has been conducted to explore the issue of energy dissipation down-stream of hydraulic structures that are constructed in open channels. Various methods and techniques have been created either to enhance the effectiveness of the current dissipaters or to find new dissipaters that are both 
highly effective and economical. These methods may be categorized as (a) energy dissipation using stilling basins, (b) energy dissipation through counter (reverse) flow, and (c) energy dissipation on sloping surfaces [5-6]. Each dissipator has certain advantages and disadvantages and may be selected and designed for a particular project depending on the site's characteristics.

Many studies have been carried out on the form, size, and details of stilling basins. In a study conduct-ed by [7] that dealt with a stilling basin provided with an intermediate sill, the impact of a constant, trans-verse sill on the hydraulic jump was evaluated. It was discovered that a sill-controlled energy dissipater could be much more effective and requires both less tailwater and duration of basin compared to free jump-ing. Further, using the presented experimental model, they described the length of the basin as the top of the bottom roller. studied the impact of the double row of baffle angels on the scour hall downstream heading up the structure [8]. They altered the position of the double row in order to obtain the best place of the baf-fles, which minimize the dimensions of the scour hall.

Energy dissipating and stilling basins have been designed in conjunction with spillways, outlet works, and canal structures. Thus, it is often necessary to conduct model studies of individual structures to be cer-tain that they will operate as anticipated. The successful drop structure of standard design for a drop height of up to 5 $\mathrm{m}$. The "Inlet drop spillway" is made up of a drop and a stilling basin. The stilling basin of this drop has an end sill and a longitudinal sill. He reported that if the tailwater level is too small, the free jump will shoot. If made longer, the velocity gradient will become low. Consequently, the stilling basin must be sufficiently lengthened so that jump and eddy areas end up inside it, resulting in increased construction ex-penses [9].

Stilling basins are seldom designed to confine the entire length of the hydraulic jump. It is possible to reduce the length of the jump via the installation of accessories such as baffles and sills in the stilling basin. These accessories contribute towards stabilitiy and shorten the jump. evaluated the impacts of using a single vertical constant sill, along with its controlling of depth and the distance of a forced jump in the stilling basin [10].

Thus, the correct design of the sill height and its place contributes significantly to the cost efficiency of the stilling basin. Many researchers have performed experimental works to increase turbulence through the hydraulic jump by using different shapes of roughness placed on the bed in order to minimize the hydraulic jump length, and consequently, the stilling basin length ,found that the T-shaped roughness saves materials and reduces this jump length when compared with the cubic one [11], indicated that the strip and inverted prismatic components decrease the length of the hydraulic jump more than the rough corrugation bed [12]. Further, examined the impact of using converged walls, which were found to be successful in stabilizing the hydraulic jump in the stilling basin instead of end sill blocks at the end of the stilling basin [13]. This research was introduced to advance the study conducted by Darweesh, by exploring the impacts of using directional diverting blocks and DDBs on ogee spillways with various downstream slopes, as well as distinct dimensions and settings.

Baffled chutes are used to dissipate the energy in the flow at drops, and to prevent the excessive accel-eration of the flow in the channel when scouring or downstream channel degradation occurs. This is achieved by using successive rows of baffle piers in the stilling basins. Specifically studied the energy dissi-pator as one of the main structures for riverbed protection. Therefore, this research examined the hydraulic phenomena produced by the installation of a sluice gate-type mobile weir and conducted a hydraulic exper-iment, with a view to suggest an effective energy dissipation technique. Through an experimental study and analysis, hydraulic characteristics, such as the length of the hydraulic jump and the installation of an energy dissipator, were formulated for applications. Moreover, this research attempted to define the design require-ments of energy dissipators for the protection of riverbeds in mobile weirs, which were inadequately reflect-ed in the current design norms. As a consequence, it was discovered that although sluice gates produced hydraulic jumps comparable to those of fixed weirs, their downstream supercritical flow improved to even-tually extend to the overall hydraulic jumps in an energy dissipator installation. Installation heights were found to be susceptible to energy dissipation. It was also found that the most efficient energy dissipator height was 10 percent of the downstream free surface water depth [14].

In previous studies that involve two rows of directional diverting blocks (DDBs) or more, the diverted flow from the prior line hits the sides of the DDBs in the next row. This leads to a decrease in the velocity of the incoming flow, and gives high turbulence, which leads to an increase in the energy dissipation. In this configuration, there is a force with the direction of flow that tries to weaken the connection between the floor and blocks. This is considered one of the limitations of using this baffle. The present study aims to make use of the straight wall baffle by attaching energy dissipaters to it, and then aims to decrease the ener-gy of the flow and minimize the hydrodynamic force. The direction of the entrance flow under sluice gates of high 
kinetic energy is diverted by using triangular shape DDBs to separate incoming flow on both sides. The diverted flow of two neighboring blocks have an opposite velocity component that impacts the SWB from both sides. Moreover, this research assesses the hydraulic performance and effectiveness of using DDBs and SWB in dissipating the energy downstream sluice gates[15-16].

\section{Theory}

In this study, the hydrodynamic force of flowed water acting on the baffle blocks in the stilling basins has to be decreased by altering the flow direction by using DDBs. Here, the energy is dissipated by the impact of the flow with the SWB on both sides. The water initially flows in a straight line, where it then collides with the triangular scattering block. The force acting on the wall can be divided into two components (tangent and normal to the wall), where the tangent forces have a slight effect on the wall, which is represented by friction force. The normal components impact the wall in the opposite direction, and the result of these forces equals zero.

The governing equations of this study are based on the one-dimensional flow of an open channel, which are continuity and energy equations. The way in which the suggested configuration are compared depends primarily on energy loss as a result of the settling basin, where the specific energy of flowing water is expressed by the following formula [7-9]:

$E=y+\frac{V^{2}}{2 g}$

where $y$ is the flow depth $(\mathrm{m}), \mathrm{V}$ is the mean velocity $(\mathrm{m} / \mathrm{s})$, and $\mathrm{g}$ is the acceleration of gravity $\left(\mathrm{m} / \mathrm{s}^{2}\right)$. The specific energy (E) of a fluid in an open channel is defined as the total mechanical energy (expressed as a head) relative to the bottom of the channel. Flow under a sluice gate, as previously mentioned, involves two flow depths that take place before and after the stilling basin. Energy losses due to the stilling basin can also be expressed as functional relationship, as in the following expression:

$\Delta \mathrm{E}$

$=\quad \mathrm{E} 1$

E2

(2)

where E1 and E2 are the specific energy upstream and downstream of the stilling basin, respectively.

Finally, the percentage of energy loss can be computed as follows:

Losses $(\%)=\frac{\Delta E}{E 1}$

(3)

Froude number Fr refers to the state of the flow and can be expressed in the following form:

$$
F r=\frac{V}{\sqrt{g y}}
$$

\section{METHODOLOGY}

The laboratory work consists of three main steps: modeling, set up of channels, and testing.

\subsection{Laboratory channel}

The flume at the University of Thi-Qar was used for the purposes of this study. The channel is $5 \mathrm{~m} \mathrm{long}, 30$ $\mathrm{cm}$ wide, and $25 \mathrm{~cm}$ high (see Figure 1). The channel also has a changing longitudinal slope. The walls and base of the channel are made of $5 \mathrm{~mm}$ thick plastic glass. It is provided with a 30 liter / s centrifugal pump to 
supply the channel with water, which collects the water at the end of the flume. To control the flow, there is a valve installed onto the pipe of the pump entering the channel at the upstream end.

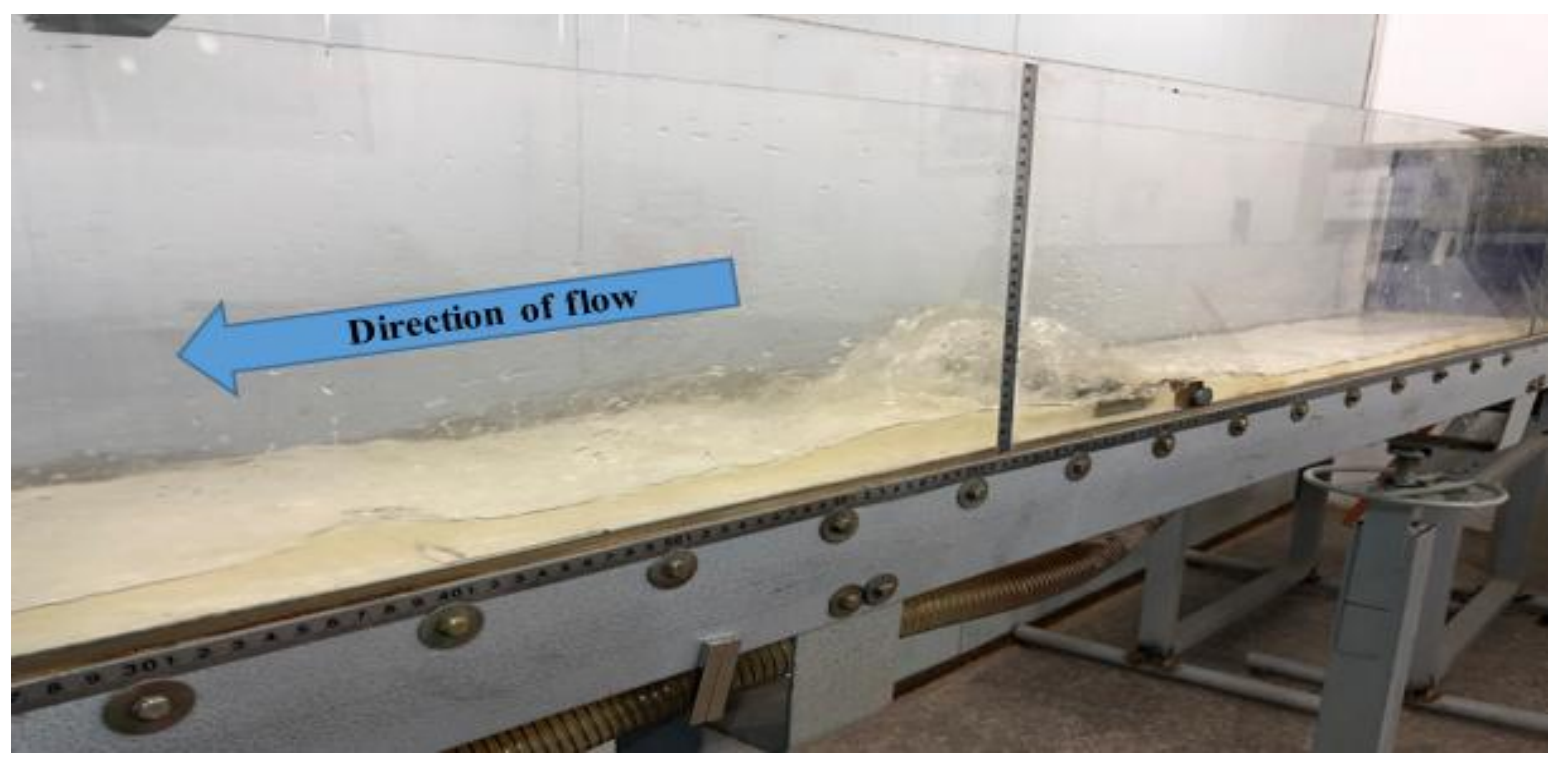

Figure 1. The general view of the channel during the run of experiments

\subsection{Manufacturing models}

In this research, two kinds of models were used to form the stilling basin in the channel. The first is constructed out of wood, covered with a material that prevents water absorption, and deforms the shape of the blocks. The wooden blocks were built in the form of a prism with fixed dimensions, by the shape of the laboratory channel used in the examination, as shown in Figure 2. There are two types of wooden prism, the first being a complete piece and the second being divided into two halves. The second type of wooden blocks are used at the walls of the channel for the purpose of symmetry. The base of the wooden prism is drilled, and then a strong magnet is attached to it with an adhesive inside this prism, which is not affected by water. The position of the blocks can be changed using another external magnet that is attached to the bottom and walls of the channel. The second kind of model is made of iron, which is resistant to corrosion and oxidation. In this test, standard pieces of rectangular magnets were used to make it easier to fasten, which had dimensions of 1 by 1 .

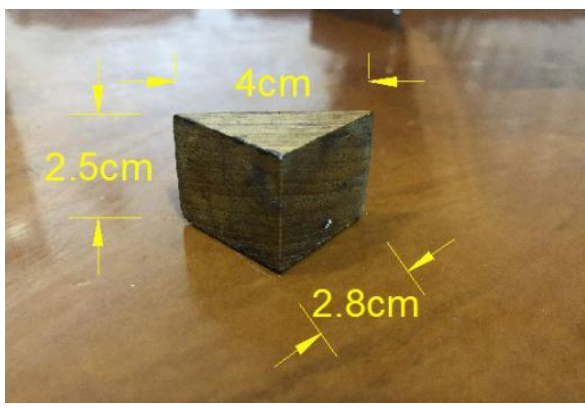

DDB

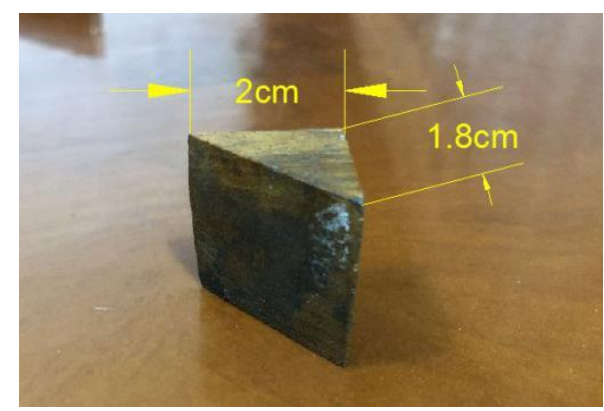

DDB at walls

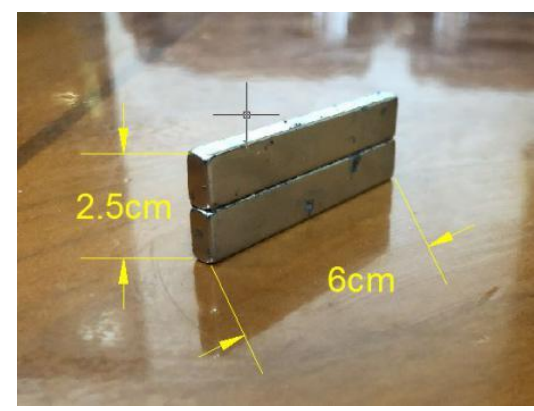

SWB

Figure 2. The models of DDBs and SWB used in the study

\subsection{Configurations}

The scheme relates to the technique and size in which the stilling basin is arranged and involves the number of rows, the configuration of DDBs, the number of units in each row, the number of block rows, and the spacing between the rows. 
Table 1 describes the setup of of the seven configurations that were used to examine the energy dissipation trials, where $\mathrm{S}$ refers to the distance between the DDBs, $d$ is the distance between the SWB, and L is the distance in which the wall is shifted from the apex of DDBs. The configurations described in Table 1 are presented in Figure 3.

Table 1. Configuration details of the stilling basin used in the test

\begin{tabular}{lllll}
\hline \hline Configuratio & Description & $\begin{array}{l}\mathrm{S} \\
\mathrm{n}\end{array}$ & $\mathrm{d}(\mathrm{cm})$ & $\mathrm{L}(\mathrm{cm})$ \\
\hline 1 & One row of DDB & 6 & ----- & ----- \\
2 & One row of DDB with SWB between them & 6 & 10 & 1 \\
3 & One row of DDB with SWB between them & 6 & 10 & 2 \\
4 & One row of DDB with SWB between them & 6 & 10 & 0 \\
5 & Two rows of DDB & 6 & ---- & ---- \\
6 & Two rows of DDB with SWB between them & 6 & 10 & 4.5 \\
7 & Two rows of DDB with SWB between them & 6 & 10 & 0.8 \\
\hline \hline
\end{tabular}

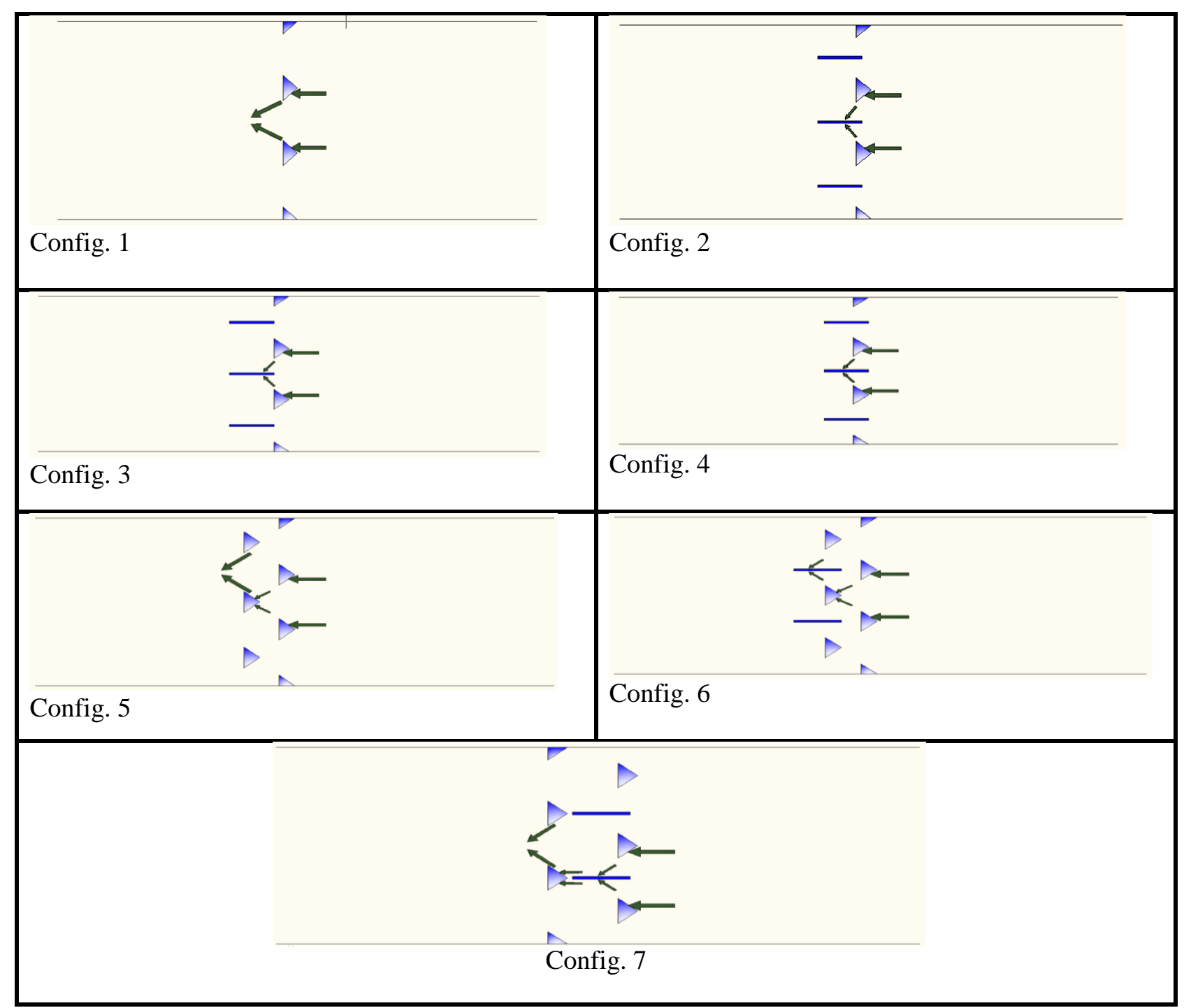

Figure 3. The schematic represents the configuration used in the experimental work. The flow direction is from right to left 


\section{Laboratory work}

Before running the experiments, the relation between the depth of the water before the gate and the discharge was determined by taking several values for the depth and calculation of the discharge by volumetric method. This relation is used later in the experiments' calculations.

In the laboratory runs, in each configuration mentioned in previous sections, the flowing parameters, discharge, flow depth before the gate, and gate opening were all measured. The water depth is measured in two locations: the first $20 \mathrm{~cm}$ after the gate and the second after the settling basin. With each configuration, four values of discharge were used, which are $0.0028 \mathrm{~m}^{3} / \mathrm{s}, 0.003 \mathrm{~m}^{3} / \mathrm{s}, 0.00315 \mathrm{~m}^{3} / \mathrm{s}$ and $0.0035 \mathrm{~m}^{3} / \mathrm{s}$, with a constant gate opening of $0.01 \mathrm{~m}$, totalling 28 runs in all.

\section{Results and analyses}

The first and most necessary step before running the experiments is to calculate discharge according to the head. These calculations are performed using the rating curve criteria. A rating curve is a relationship between the discharge Q and head $\mathrm{H}$. In the calculations of the rating curve (see Figure 4), there are several values of the head, i.e. the water depth upstream the sluice gate, and the collected volumes of water based on a specified gate opening of $0.01 \mathrm{~m}$. In particular, the discharge coefficient is computed to be 0.53 .

In this paper, we presented 28 cases of energy dissipation configurations based on the suggested scheme. These cases were characterized by four pair values of data of heads and discharges $(\mathrm{H}, \mathrm{Q}),(0.16 \mathrm{~m}, 0.0028$ $\left.\mathrm{m}^{3} / \mathrm{s}\right),\left(0.19 \mathrm{~m}, 0.003 \mathrm{~m}^{3} / \mathrm{s}\right),\left(0.20 \mathrm{~m}, 0.00315 \mathrm{~m}^{3} / \mathrm{s}\right)$, and $\left(0.25 \mathrm{~m}, 0.0035 \mathrm{~m}^{3} / \mathrm{s}\right)$.

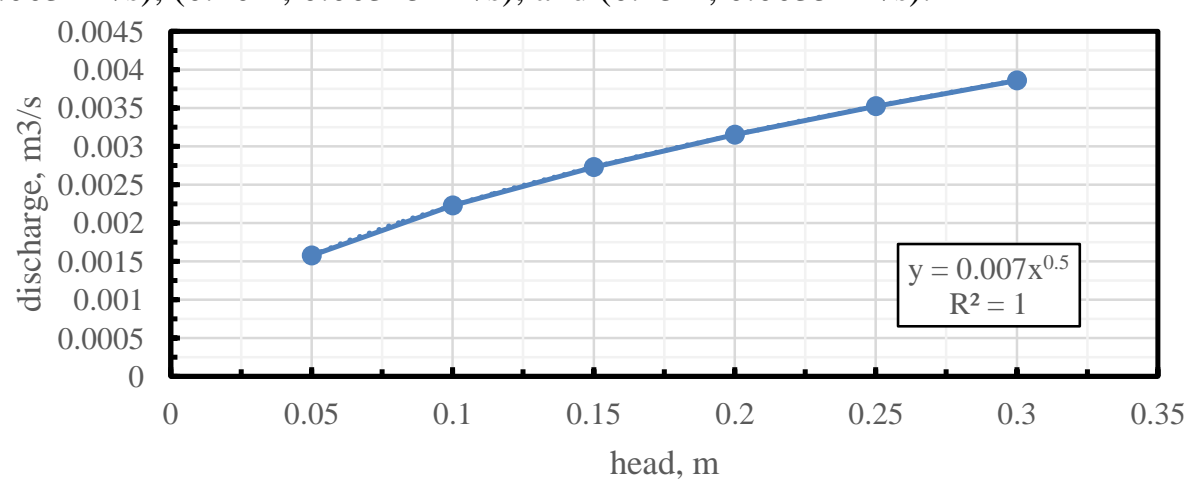

Figure 4. Rating curve of the flume

Figure 5 shows one example of the experiments' run, i.e. configuration 7 in Figure 3, where the flow direction is from right to left. Figure 5 clearly shows that there is a sharp discontinuity in the water surface, and thus a considerable amount of energy is dissipated due to turbulence from the impact. It is essential to mention that since the length of the jump is short, the losses due to shear at the channel bottom and the sides are small when compared to the present forces, and thus can be neglected. Moreover, since the channel is horizontal, the component of the weight of water in the downstream direction is zero.
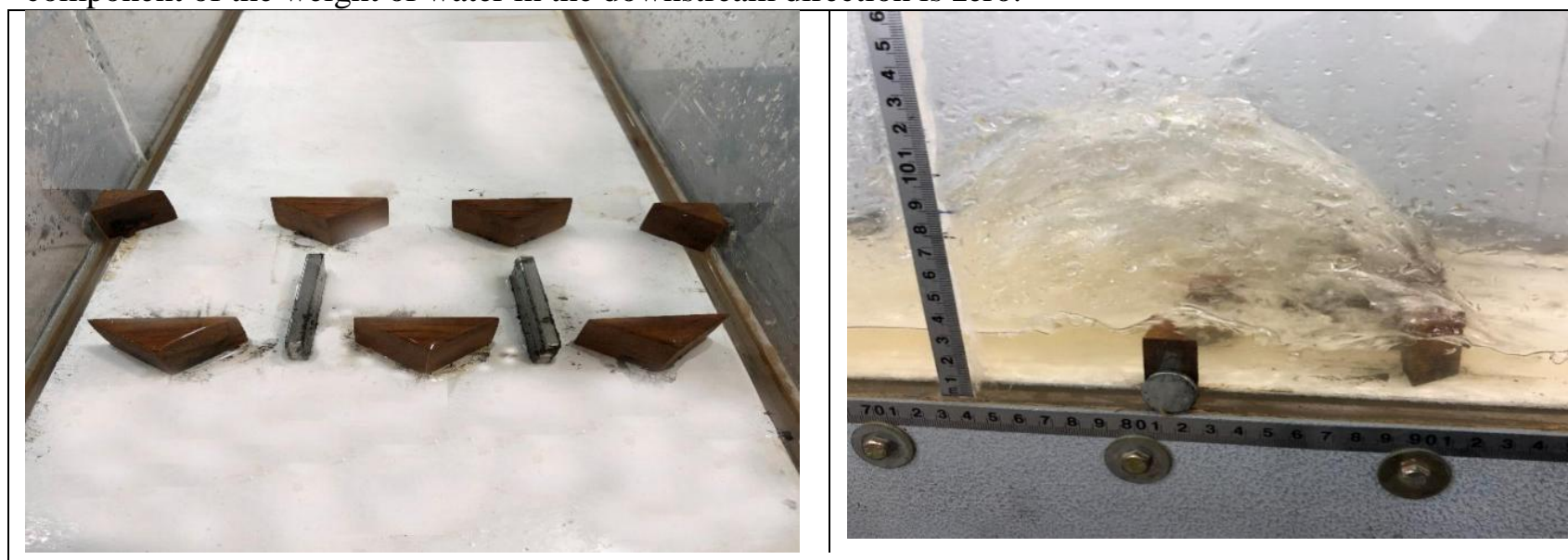

Figure 5. Implementation runs of the experiments, provided as an example. The image on the left represents the configuration setup and the image on the right is during the run. The flow direction is from right to left and all dimensions are in $\mathrm{cm}$ 


\subsection{Energy dissipations}

In this study, we calculate the percentage of energy losses based on equation (3). The findings show that the largest percentage of head losses resulted from configuration 7 for all discharge values, as shown in Figure 6 . This can be clearly seen in Figure (3), where the running water collides with the dispersion blocks and the wall three times and once with the water itself. Configuration 6 gives the second largest percentage of energy dissipation. In this case, the collision was obtained only with the dispersion blocks and the wall, without colliding with itself. Meanwhile, configuration 5 gives less energy than what is produced from configuration 6 , where in the configuration 5 the incoming water in the channel collides twice, first with the DDBs, and second with itself. The results show that the percentage of dissipated energy due to using configuration 2 is significantly less than the dissipated energy when using configuration 6 . This is attributed to the flow in configuration 2, which collides with the block change direction and the wall only. It is clear from Figure 6 that the dissipated energy that comes from configurations 3 and 4 is not far away from the dissipated energy that resulted from using configuration 2. However, the disturbance in the flow is lower because the wall lags beyond the previous one. Finally, configuration 1 produced the least dispersion rate of energy as it consists of only one row of blocks (DDB) without a wall buffer. Figure 7 illustrates the outcomes of all the experiments and all the release values. Based on Figure 6, it is clear that the rate of dispersion of energy increases with the discharge. This implies that the velocity is improved before the settling basin owing to depth stabilization (y1). The results also showed (see Figure 7) that the Froud number (Fr) after the stilling basins for all discharges was smaller in the basins of greater dispersion energy, and it reduces when increasing the discharge. It can be observed from Figure 8 that there is an obvious downward trend in thes Froud number with an increasing discharge for all configurations. However, this trend is largest in the case of configuration 7.

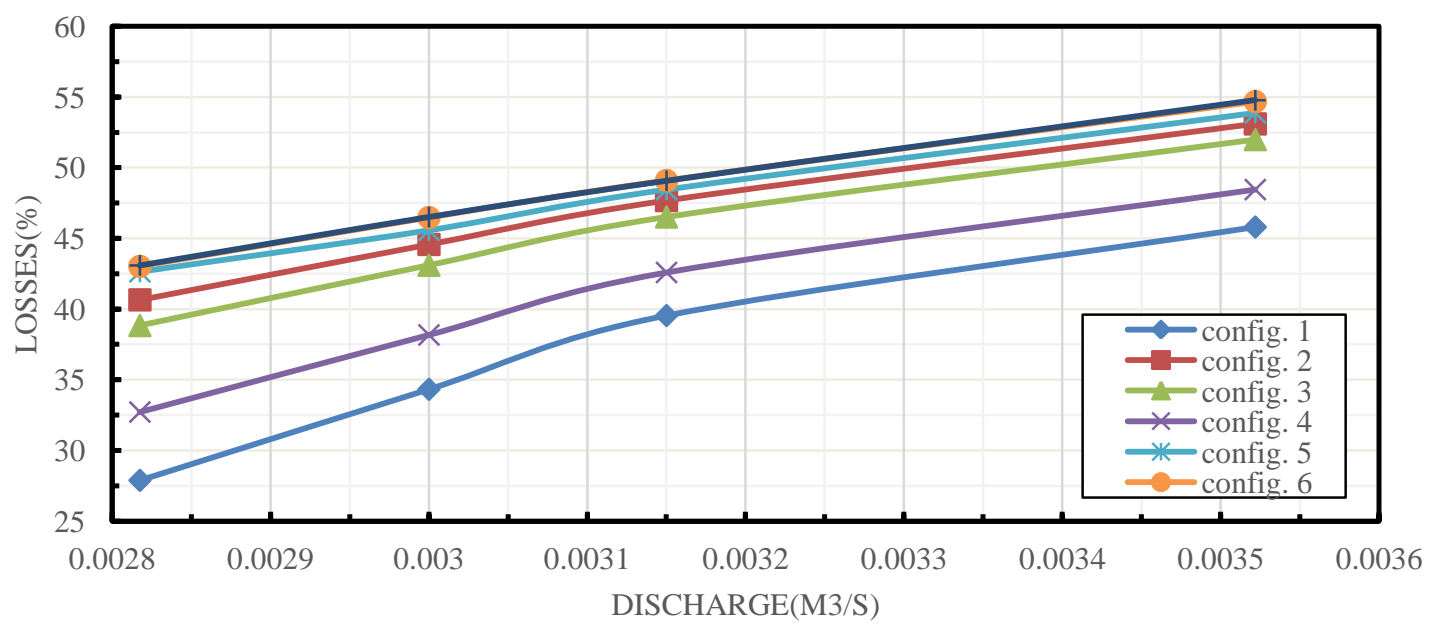

Figure 6. Variation of the head losses with discharges for all configurations

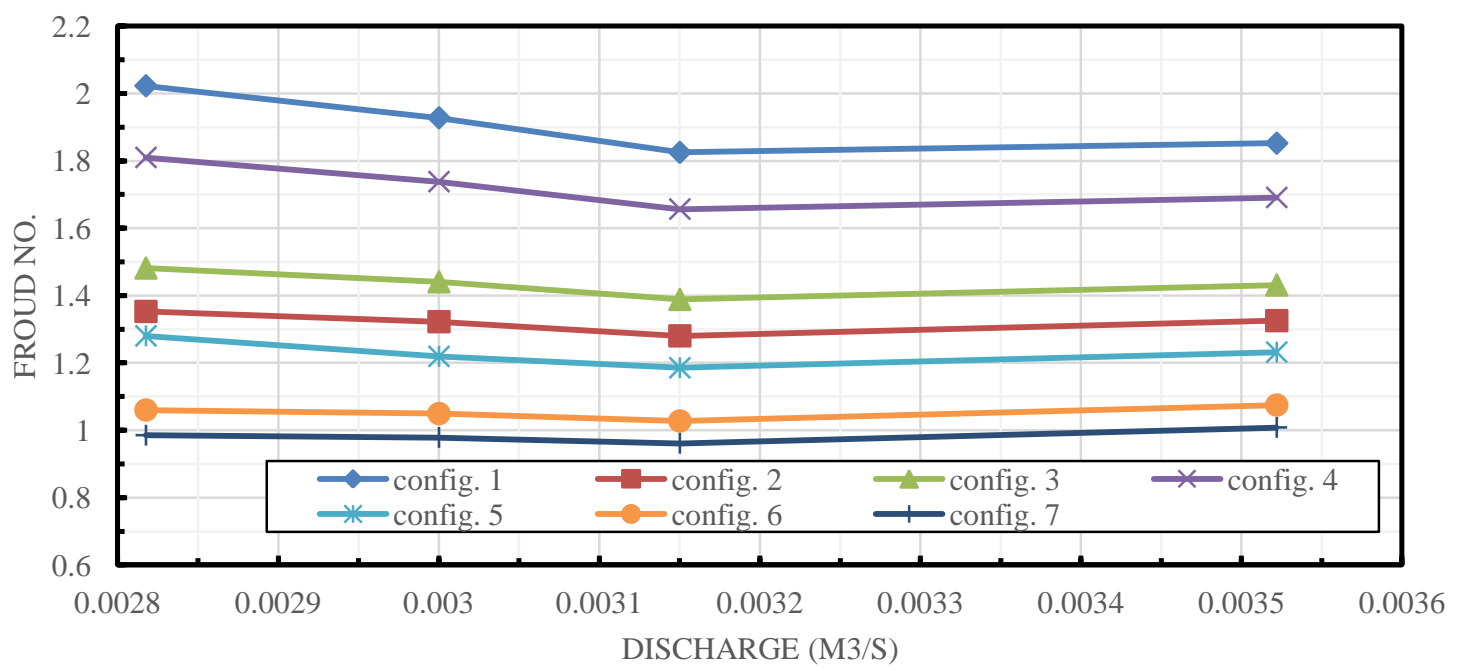

Figure 7. Variation of the Froud number (Fr) with discharge for all the configurations 


\subsection{Downstream conditions}

Studies of channel changes below structures, such as regulators, have predominantly been concerned with the process of channel bed erosion induced by high flow velocity and water depths at the downstream (Qassem et al., 2014). Thus, our specific goal here is to focus on the percentage of reduction in flow velocity (V1-V2)/V1, and the increase in the water depth (y) due to using one of the studied configurations. Figures 9 and 10 depict the study's results, showing the change in reduction in flow velocity and flow depth (respectively), with the discharge for all the configurations. The results show that the percent of reduction of flow velocity, and thereby the flow depth, increases when increasing the percent of energy dissipation (see figures 8 and 9).

Table 2 provides a review of the results of the seven cases used in this study, where in each case, there are four types of discharges. Each discharge takes place at a certain depth and gives a Froud number that determines the type of the flow. In each case, the loss of water energy in the channel is calculated due to the presence of dispersants.

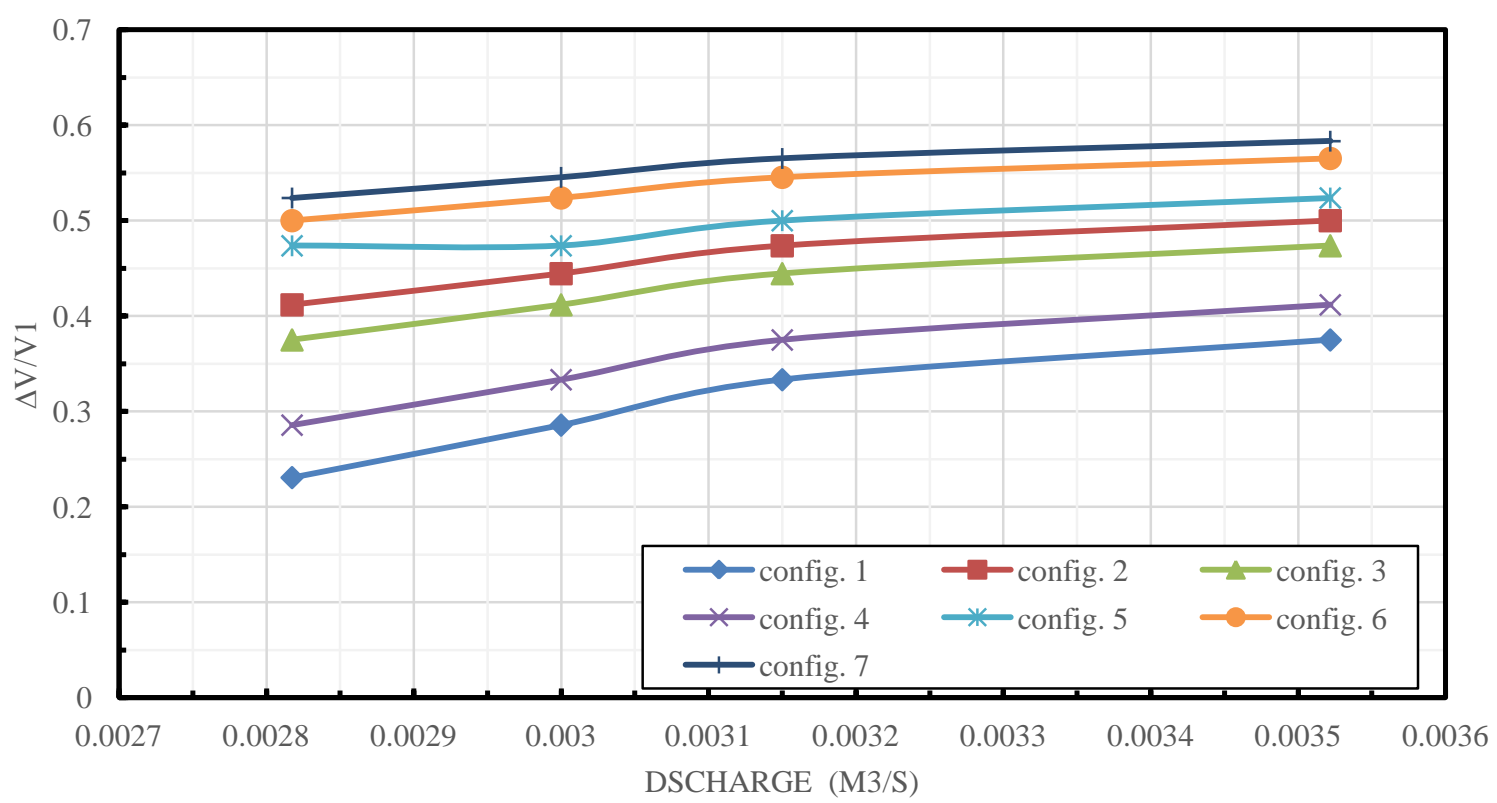

Figure 8 . Variation of the percent of velocity reduction with the discharge at the downstream end

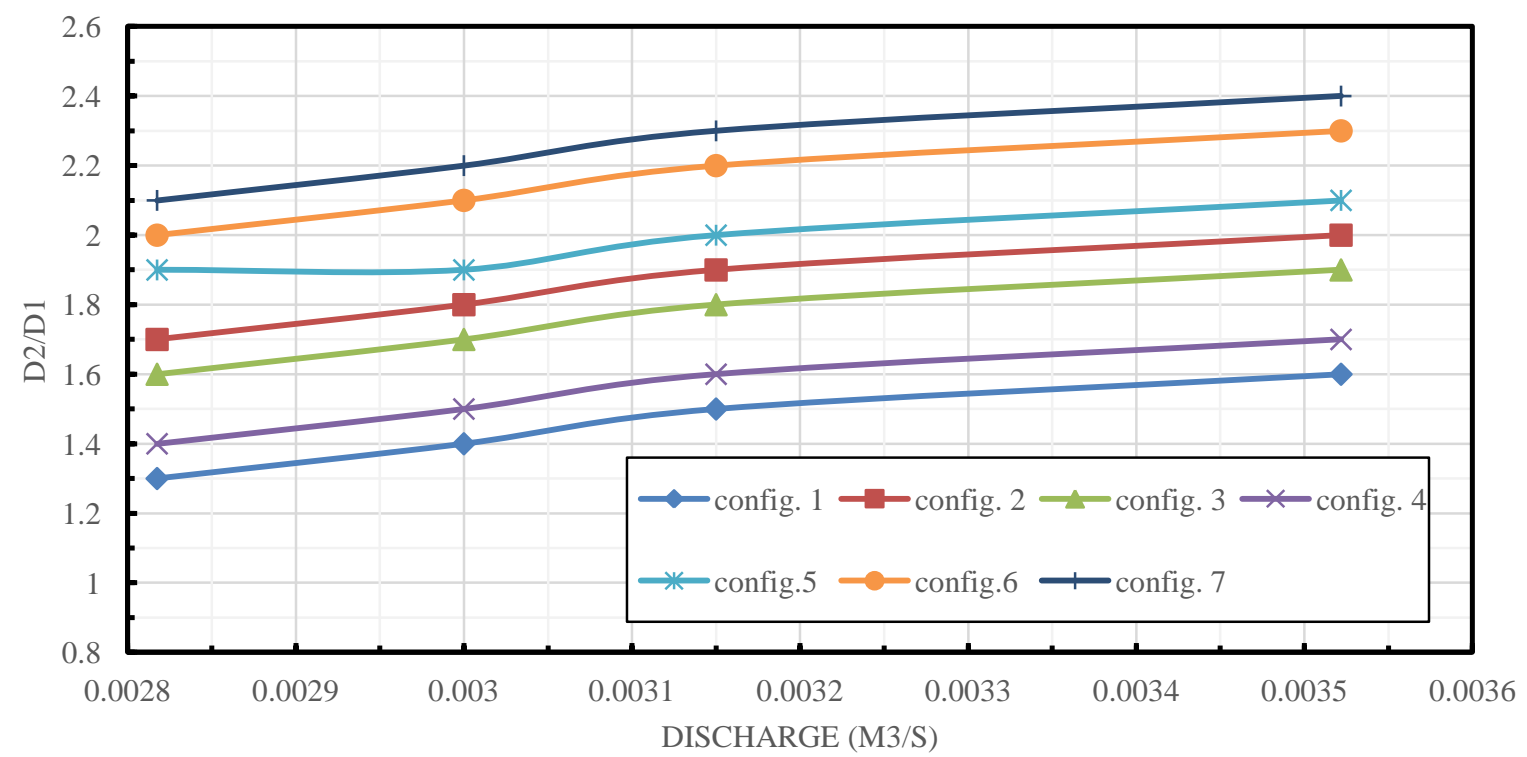

Figure 9. Variation of the depth ratio with the discharge at the downstream end. Where $\mathrm{d} 2$ is the depth at the downstream and $\mathrm{d} 1$ is the depth at the upstream for the same used discharge 
Table 2. Results of the seven cases used in this study

\begin{tabular}{lllll}
\hline Configuration & Discharge, $\mathrm{m}^{3} / \mathrm{s}$ & $\mathrm{d} 2, \mathrm{~m}$ & Fr. 2 & $\begin{array}{l}\text { Eneergy } \\
\text { losses, } \%\end{array}$ \\
\hline \multirow{3}{*}{1} & 0.002817 & 0.013 & 2.02 & 27.88 \\
& 0.003000 & 0.014 & 1.93 & 34.32 \\
& 0.003150 & 0.015 & 1.82 & 39.54 \\
2 & 0.003522 & 0.016 & 1.85 & 45.80 \\
& 0.002817 & 0.017 & 1.35 & 40.65 \\
& 0.003000 & 0.018 & 1.32 & 44.57 \\
& 0.003150 & 0.019 & 1.28 & 47.67 \\
3 & 0.003522 & 0.02 & 1.33 & 53.10 \\
& 0.002817 & 0.016 & 1.48 & 38.83 \\
& 0.003000 & 0.017 & 1.44 & 43.10 \\
4 & 0.003150 & 0.018 & 1.39 & 46.51 \\
& 0.003522 & 0.019 & 1.43 & 51.98 \\
& 0.002817 & 0.014 & 1.81 & 32.72 \\
5 & 0.003000 & 0.015 & 1.74 & 38.17 \\
& 0.003150 & 0.016 & 1.66 & 42.59 \\
& 0.003522 & 0.017 & 1.69 & 48.45 \\
& 0.002817 & 0.019 & 1.14 & 42.63 \\
6 & 0.003000 & 0.019 & 1.22 & 45.57 \\
& 0.003150 & 0.02 & 1.19 & 48.45 \\
& 0.003522 & 0.021 & 1.23 & 53.88 \\
& 0.002817 & 0.02 & 1.06 & 43.01 \\
7 & 0.003000 & 0.021 & 1.05 & 46.47 \\
& 0.003150 & 0.022 & 1.03 & 49.09 \\
& 0.003522 & 0.023 & 1.07 & 54.67 \\
& 0.002817 & 0.021 & 0.99 & 43.09 \\
& 0.003000 & 0.022 & 0.98 & 46.50 \\
& 0.003150 & 0.023 & 0.96 & 49.07 \\
& 0.003522 & 0.024 & 1.01 & 54.77 \\
\hline
\end{tabular}

\section{Conclusions}

In this study, we presented 21 arrangements of proposed energy dissipation in stilling basins. These configurations are performed in seven different cases, based on the arrangement of the block and wall, in order to change the direction of flow and then dissipate the energy. For the discharges, three different values are used to run the experiments. The discharge competitions are done with laboratory data of discharge and upstream head, using the rating curve to generate the relation between the head and the discharge. Then, the performed rating carve is used to compute the discharge for the head that is used in the experiments. The pertinent conclusions reached in this study are as follows:

1. The proposed arrangement, characterized by two rows of DDB with SWB between them, is highly efficient $(\sim 55 \%)$ in dispersing energy when compared with other proposed configurations.

2. In all the proposed constructions with two or more rows arrangements, the wood blocks are more effective at dissipating the energy than the iron walls, but they are subject to hydrodynamic forces in the flow direction. 3. In a high flow condition, it is vulnerable to place the walls on the shock blocks, because of the results of the hydrodynamic forces on the blocks reaches zero, and thus become more stable than the others.

\section{References}

[1] M. Abdel Azim ,M. Gamal , A. Abdel Aal , and A. Habib. Effect of End Sill In Radial Basin On Characteristics Of Free Hydraulic Jump, Water Structure Engineering, Faculty of Engineering, University of ZagaZig , Egypt,2012.

[2] N. AboulAtta , G. Ezizah, N. Yousif , and S. Fathy. Design of Stilling Basin Using Artificial Roughness, International Journal of Civil and Environmental Engineering,2011.

[3] A. Alikhani, R. Behrozi, and M. Fathi. Hydraulic jump In Stilling Basin With Vertical End Sill, Journal of Physical Sciences, Department of Civil Engineering, University of Qom, Iran,2009. 
[4] K. R. Arora . Irrigation Water Power and water Resources Engineering, NaiSarak, Delhi, A. K. Jain for Standard Publishers Distributors,2007.

[5] M. A. Awad . Design of Stilling Basins Downstream Drop Structures. M. Sc. Thesis, Zagazig University, Zagazig, Egypt,2004.

[6] E. F. Brater, H. W. King , J. E. Lindell , and C. Y. Wei. Handbook of Hydraulics, Seventh Edition, USA, published by McGraw-Hill Book Company,1996.

[7] T. J. Ntayeesh, M. R. Ismail, R. G. Saihood, and A. Info, "Buckling analysis of reinforced composite plates with a multiwall carbon nanotube ( MWCNT )," Period. Eng. Nat. Sci., vol. 7, no. 3, pp. 1275$1285,2019$.

[8] H. R. Abdulshaheed, I. Al Barazanchi, H. T. Jaya, and D. Tunggal, "Smart Solutions Based-On Cloud Computing and Wireless Sensing," Int. J. Adv. Sci. Technol., vol. 28, no. 8, pp. 526-542, 2019.

[9] V. T. Chow. Open-Channel Hydraulics. published by McGraw-Hill Book Company,1959.

[10] A. N. Darweesh . Energy Dissipation In Mandili Dam Spillway Stilling Basin By Using Direction Diverting Blocks,M. Sc. dissertation presented to the University of Baghdad, College of Engineering,2012.

[11] A. A. EL-Masry. Minimization of Scour Downstream Heading Up Structure Using Double Lines Of Angle Baffle. Sixth International Water Technology (IWTC), Alexandria, Egypt, 2001.

[12] Y. Kim , Gyewoon Choi, Hyoseon Park and Seongjoon Byeon . Hydraulic Jump and Energy Dissipation with Sluice Gate. Water , 7, 5115-5133,2015. doi:10.3390/w7095115.

[13] A. J. Peterka . Hydraulic design of stilling basins and energy dissipators (No. 25). Department of the Interior, Bureau of Reclamation, 1978.

[14] M. R. Pirestani , A. Razmkhah , and F. Ghobadi. Effect of Convergent Walls on Energy Dissipation in Stilling Basin by Physical Modeling, International Journal of Thermal and Fluid Sciences ,2012.

[15] H. J. Qassem, N. F. Al-Baaja . Experimental study for energy dissipation using stilling basin with one and two consecutive drops. Diyala journal of engineering science. Vol. 07, No. 02, pp. 16-28, June 2014.

[16] R. Al-Zubaidy, K. R. Al-Murshidi . Energy Dissipation By Using Different Sizes And Configurations Of Direction Diverting Blocks On Spillways. Journal of Babylon University/Engineering Sciences/ No. (2)/ Vol. (22): 2014. 